\title{
Smad3 and phospho-Smad3 are potential markers of invasive nonfunctioning pituitary adenomas
}

This article was published in the following Dove Press journal:

OncoTargets and Therapy

15 April 2016

Number of times this article has been viewed

\section{Chunhui Liu ${ }^{1,2}$ \\ Zhenye $\mathrm{Li}^{1-3}$ \\ Dan $\mathrm{Wu}^{4}$ \\ Chuzhong $\mathrm{Li}^{\mathrm{I}-3}$ \\ Yazhuo Zhang ${ }^{1-3}$}

'Beijing Neurosurgical Institute, Capital Medical University, ${ }^{2}$ Beijing Institute for Brain Disorders, Brain Tumor Center, ${ }^{3}$ Department of Neurosurgery, Beijing Tiantan Hospital, Capital Medical University, ${ }^{4}$ Department of Neurology, Beijing Renhe Hospital, Beijing, People's Republic of China
Correspondence: Yazhuo Zhang Beijing Neurosurgical Institute, Capital Medical University, 6 Tiantan Xili, Dongcheng District, Beijing 100050, People's Republic of China Tel +861067096763

Fax +86106705 7391 Email zyz2004520@yeah.net
Background: Transforming growth factor- $\beta$ (TGF- $\beta$ ) signaling plays important roles in tumor development. Nevertheless, the roles of TGF- $\beta /$ Smad signaling in nonfunctioning pituitary adenomas (NFPAs) have not been fully studied.

Methods: Tumor samples were obtained from patients who had NFPAs and underwent endoscopic transsphenoidal surgery or craniotomy at Beijing Tiantan Hospital from March 2008 to December 2012. Immunohistochemistry was performed to determine the expression of Smad transducer proteins in NFPAs. Ki-67 was evaluated as an indicator of the proliferative activity of NFPAs.

Results: A total of 161 patients with NFPAs were identified; 59 (36.6\%) had invasive NFPAs and $102(63.4 \%)$ had noninvasive NFPAs. Protein levels of Smad3 and phospho-Smad3 (p-Smad3) were significantly lower in patients with invasive NFPAs than in patients with noninvasive NFPAs $(P<0.05$ and $P<0.01$, respectively). The Ki-67 index was markedly greater in invasive NFPAs than in noninvasive NFPAs $(P<0.05)$ and was significant correlated with p-Smad3 levels $(P<0.05, r=-0.702)$.

Conclusion: A low level of Smad3 and p-Smad3 proteins was associated with the invasion of NFPAs.

Keywords: nonfunctioning pituitary adenoma, invasion, transforming growth factor- $\beta$, Smad, $\mathrm{Ki}-67$

\section{Introduction}

Pituitary adenomas (PAs), with a prevalence of 80-90/100,000 people, ${ }^{1,2}$ comprise $\sim 15 \%$ of intracranial tumors. Majority of PAs secrete pituitary hormones, resulting in elevated blood hormone levels and clinical syndromes. Nonfunctioning pituitary adenomas (NFPAs) constitute $~ 30 \%$ of PAs and do not cause clinical hormone hypersecretion. ${ }^{3}$ Most PAs are histologically benign. However, as hormonal inactivity leads to delayed diagnosis, a part of NFPAs becomes invasive. ${ }^{4}$ Invasive NFPAs often invade cavernous sinus; hence, curative radical surgery becomes difficult. In addition, there are no effective drugs for NFPAs and radiotherapy remains controversial. Therefore, NFPAs are a therapeutic challenge.

The effects of transforming growth factor- $\beta$ (TGF- $\beta$ ) signaling are diverse in different tumor periods and tumor types. ${ }^{5-7}$ TGF- $\beta$ ligands carry out biological effects by binding to TGF- $\beta$ receptor complexes (TGF- $\beta$ RI/II) and activating them. Smads are TGF- $\beta$ signal transducer proteins. Activated TGF- $\beta$ receptor complexes can phosphorylate Smad2 and Smad3, which associate with Smad4 to form a complex to get into the nucleus and regulate transcriptional activity. Smad7 is an inhibitory factor that restrains the phosphorylation of Smad2 and Smad3..$^{7-9}$ 
It has been suggested that TGF- $\beta /$ Smad signaling may be associated with the development and invasion of NFPAs in our previous work. ${ }^{10}$ However, the validity of this conclusion remains uncertain due to a small sample size and potential selection bias. Therefore, we built a PA database at Beijing Tiantan Hospital, which includes information on all patients with PAs. In this study, with the use of the database, we aimed to investigate whether TGF- $\beta /$ Smad signaling is associated with the invasion of NFPAs and evaluate the proliferative activity (Ki-67) in NFPAs.

\section{Materials and methods}

\section{Patients and specimens}

From March 2008 to December 2012, patients with NFPAs who underwent endoscopic transsphenoidal surgery or craniotomy at Beijing Tiantan Hospital were included in this study. Patients with previous radiation therapy or recurrence were excluded. NFPA was diagnosed according to clinical feature, hormonal levels, magnetic resonance imaging, histopathological examination, and immunohistochemical staining for all anterior pituitary hormones. Invasive PAs were defined as Knosp classification grade IV. ${ }^{11}$ NFPA samples were obtained from patients, and immunohistochemistry was performed to evaluate protein levels. The study protocol was approved by the Ethics Committee of Beijing Tiantan Hospital, and written informed consent was obtained from all the patients.

\section{Tissue microarray}

Formalin-fixed, paraffin-embedded tissue blocks were sliced, and hematoxylin-eosin-stained slides were produced. Three core biopsies with a $2.0 \mathrm{~mm}$ diameter were selected from the paraffin-embedded tissues. The cores were transferred to tissue microarray (TMA) using the Minicore tissue-arraying instrument (Mitogen, Alphelys, France). Samples were randomly ordered and anonymized on the TMA slides. TMAs were cut into $4 \mu \mathrm{m}$ sections using a serial microtome.

\section{Immunohistochemistry}

All the TMA slides were evaluated in advance using a hematoxylin-eosin staining to assess tumor content and quality. The TMAs were placed in a Leica BOND-III arrayer (Leica Microsystems, Wetzlar, Germany), which is a fully automated, random, and continuous access slide staining system that processes immunohistochemistry tests simultaneously. Bond ${ }^{\mathrm{TM}}$ Polymer Refine Detection (Leica Microsystems) was used for the detection of primary antibodies. Immunostainings were standardized using appropriate positive and negative controls for each antibody. All the TMAs were stained in the same run for each antibody to avoid interassay variability. The slides were digitally scanned, and protein expression was examined using Aperio AT2 (Leica Microsystems). The following antibodies were used: Ki-67 (1:100; Abcam, Cambridge, UK), Smad2 (1:100; Abcam), phospho-Smad2 (p-Smad2; Ser465/467) (1:100; Abcam), Smad3 (1:100; Abcam), p-Smad3 (Ser423/425) (1:100; Abcam), and Smad4 (1:100; Abcam).

The sections were examined and scored by two pathologists who were unaware of clinical records of patients. For Smad2, Smad3, and Smad4, the cytoplasmic staining pattern was considered to be the positive expression. For p-Smad2 and p-Smad3, the nuclear staining pattern was considered to be the positive expression. Five fields at $200 \times$ magnification were randomly selected. A semiquantitative system was used to evaluate the staining scores. The proportion of positive cells was scored as follows: $0(<5 \%), 1$ (6\%-25\%), $2(26 \%-50 \%), 3(51 \%-75 \%)$, and $4(>75 \%)$. Staining intensity was evaluated as follows: 0 (no staining), 1 (weak staining, light yellow), 2 (moderate staining, yellowish brown), and 3 (strong staining, brown). Sum score was determined by multiplying the positive proportion score by intensity score: negative ( 0 ), weakly positive (1-4), moderately positive (5-8), and strongly positive (9-12). In this study, the expression was considered low expression when the score was less than nine, and high expression when the score was $\geq 9$. $^{12}$

\section{Statistical analysis}

SPSS software (version 16.0; SPSS Inc., Chicago, IL, USA) was used for statistical analysis. Data were expressed as mean \pm standard deviation. Differences between the groups were determined by one-way analysis of variance or independent two-sample Student's $t$-test. Correlation analysis was assessed by Spearman's rank correlation. $P<0.05$ was considered statistically significant.

\section{Results}

\section{Patient characteristics}

A total of 161 patients with NFPA who underwent endoscopic transsphenoidal surgery or craniotomy were included in this study. These patients had a medium age of 52 years; $98(60.9 \%)$ were men and $63(39.1 \%)$ were women. Of the 161 patients, $59(36.6 \%)$ had invasive NFPAs and 
Table I Characteristics of patients

\begin{tabular}{|c|c|c|}
\hline Characteristic & $\begin{array}{l}\text { Invasive NFPAs } \\
(\mathrm{N}=59) \text { mean } \pm \text { SD }\end{array}$ & $\begin{array}{l}\text { Noninvasive NFPAs } \\
(\mathrm{N}=102) \text { mean } \pm \text { SD }\end{array}$ \\
\hline Age, (years), no (\%) & $49.0 \pm 11.5$ & $51.8 \pm 10.7$ \\
\hline \multicolumn{3}{|l|}{ Sex } \\
\hline Male, no (\%) & 37 (62.7) & $61(59.8)$ \\
\hline \multicolumn{3}{|l|}{ Symptom, no (\%) } \\
\hline Headache & $35(59.3)$ & $72(70.6)$ \\
\hline Visual deficit & $28(47.5)$ & $36(35.3)$ \\
\hline Hypopituitarism & 20 (33.9) & $17(16.7)$ \\
\hline None & $2(3.4)$ & I5 (14.7) \\
\hline \multicolumn{3}{|c|}{ Tumor size $(\mathrm{cm})$, no (\%) } \\
\hline$<3$ & $8(13.6)$ & $79(77.5)$ \\
\hline$\geq 3$ & $51(86.4)$ & $3(22.5)$ \\
\hline
\end{tabular}

Abbreviations: NFPAs, nonfunctioning pituitary adenomas; SD, standard deviation.

$102(63.4 \%)$ had noninvasive NFPAs (Table 1). Visual deficit and hypopituitarism were more common in patients with invasive NFPAs than in patients with noninvasive NFPAs, and tumor size was larger in patients with invasive NFPAs than in patients with noninvasive NFPAs.

\section{Expression of Smad2 and p-Smad2 in NFPAs}

To determine the expression of Smad2 and $\mathrm{p}-\mathrm{Smad} 2$ in invasive and noninvasive NFPAs, we evaluated the protein levels of Smad2 and p-Smad2 by immunohistochemistry. We found that there was no significant difference in the Smad2 or p-Smad2 protein levels between invasive and noninvasive NFPAs (Figure 1). Smad2 was highly expressed in $33.9 \%$ (20 of 59 cases) of invasive NFPAs and 29.4\% (30 of 102 cases) of noninvasive NFPAs $(P=0.553)$. $\mathrm{p}-\mathrm{Smad} 2$

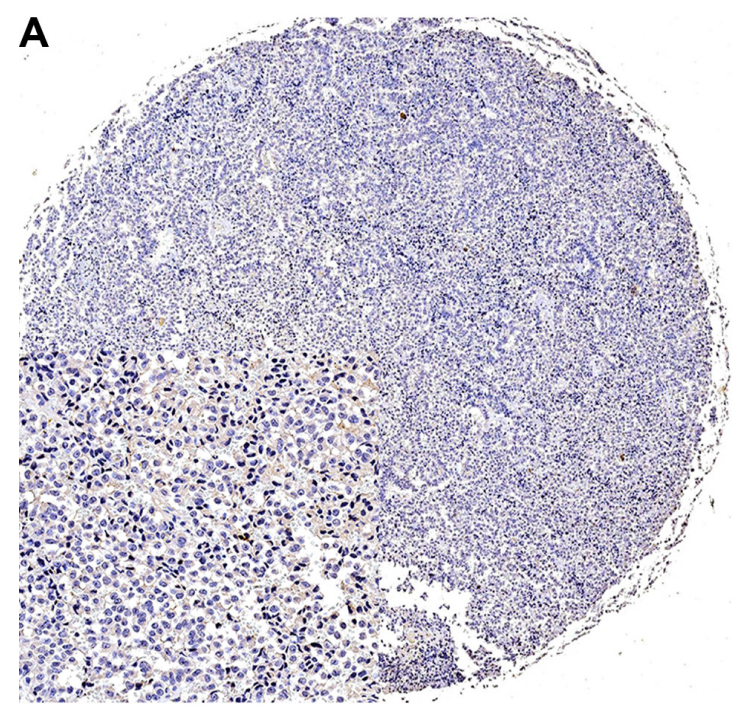

was highly expressed in $39.9 \%$ (23 of 59 cases) of invasive NFPAs and $33.3 \%$ (34 of 102 cases) of noninvasive NFPAs $(P=0.470)$.

\section{Expression of Smad3 and p-Smad3 in NFPAs}

Next, we sought to investigate the protein levels of Smad3 and $\mathrm{p}-\mathrm{Smad} 3$ by immunohistochemistry in invasive and noninvasive NFPAs. Surprisingly, we found that the protein levels of Smad3 and p-Smad3 were significantly lower in invasive NFPAs than in noninvasive NFPAs (Figure 2). Smad3 was highly expressed in $15.3 \%$ (nine of 59 cases) of invasive NFPAs and $31.4 \%$ (32 of 102 cases) of noninvasive NFPAs $(P<0.05)$. p-Smad3 was highly expressed in $10.2 \%$ (six of 59 cases) of invasive NFPAs and 40.2\% (41 of 102) of noninvasive NFPAs $(P<0.01)$.

\section{Expression of Smad4 in NFPAs}

We then investigated the protein levels of Smad4 by immunohistochemistry in invasive and noninvasive NFPAs. We found that there was no significant difference in the Smad4 protein levels between invasive NFPAs and noninvasive NFPAs (Figure 3). Smad4 was highly expressed in $37.3 \%$ (22 of 59 cases) of invasive NFPAs and 36.3\% (37 of 102 cases $)$ of noninvasive NFPAs $(P=0.898)$.

\section{Expression of $\mathrm{Ki}-67$ in NFPAs}

$\mathrm{Ki}-67$ can serve as an indicator of proliferative activity in NFPAs. We thus evaluated the levels of Ki-67 by immunohistochemistry in invasive and noninvasive NFPAs. We found

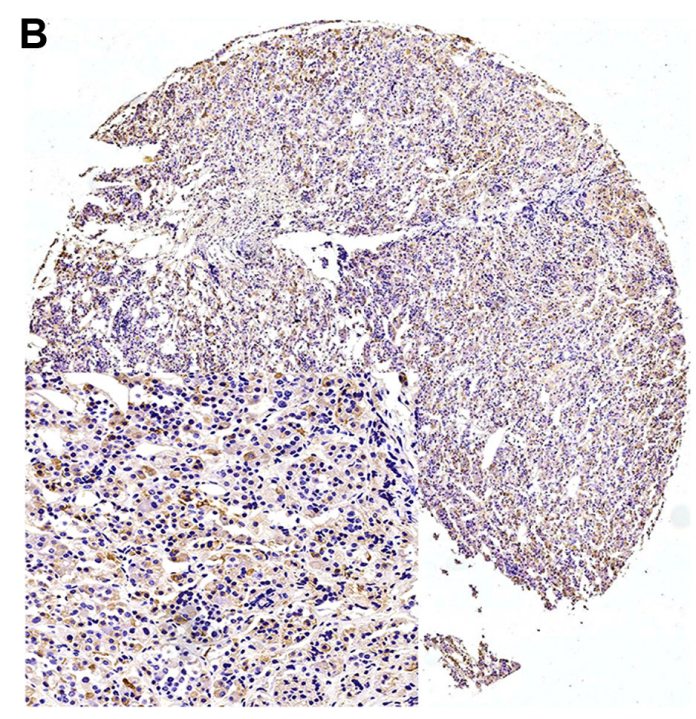

Figure I (Continued) 

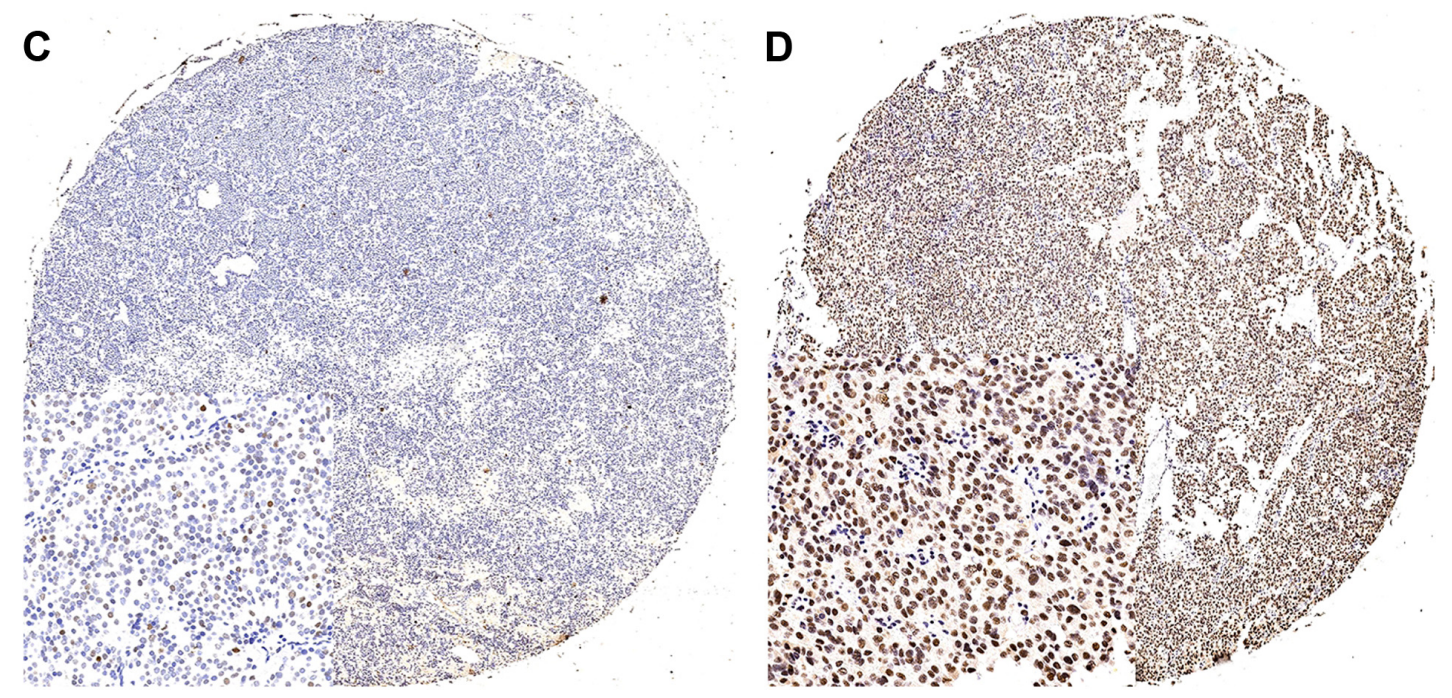

Figure I Smad2 and p-Smad2 expression in NFPAs.

Notes: (A) Low expression of Smad2, (B) high expression of Smad2, (C) low expression p-Smad2, (D) high expression p-Smad2; (A-D) magnification: 200×. Abbreviation: NFPAs, nonfunctioning pituitary adenomas.
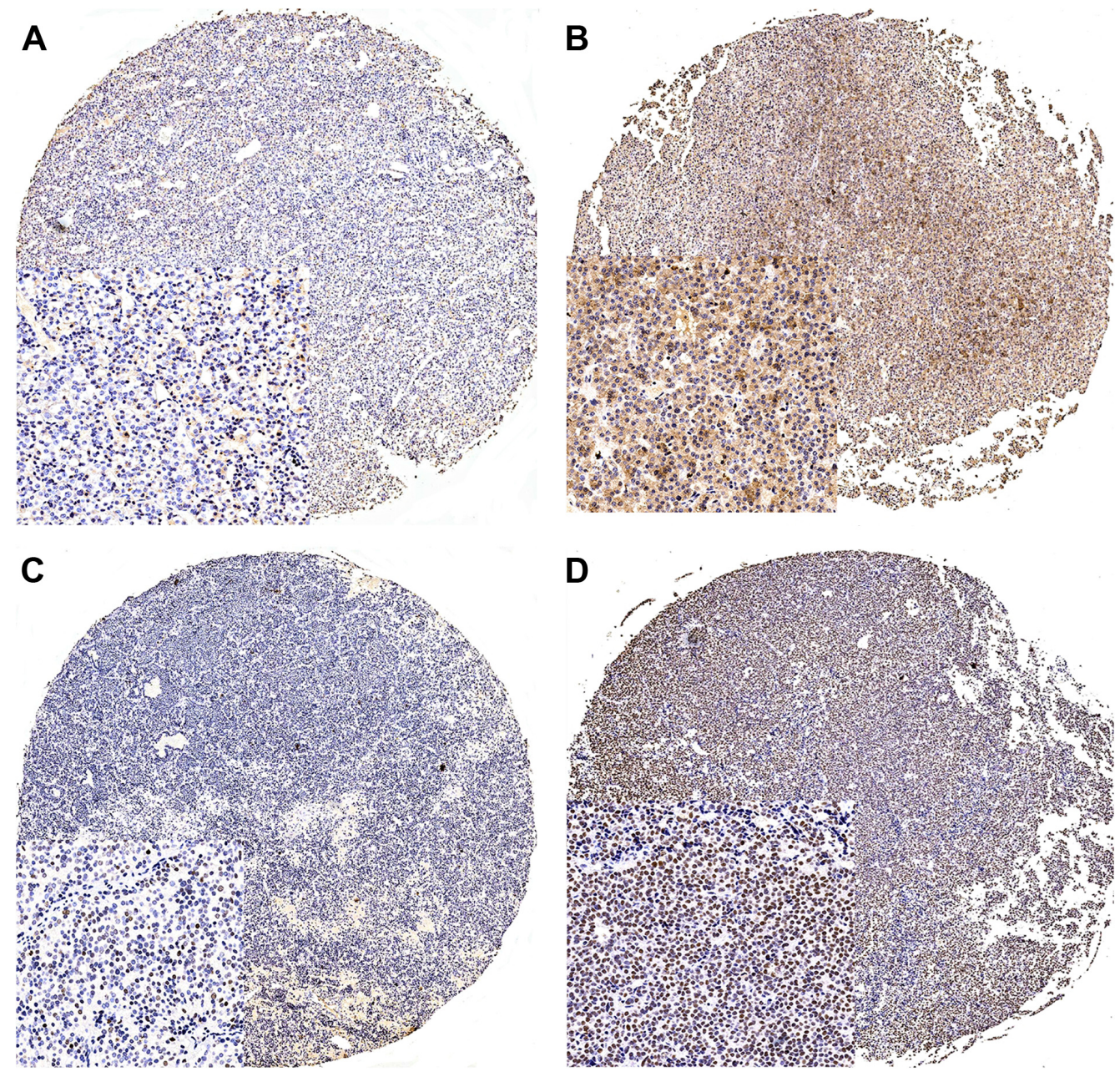

Figure 2 Smad3 and p-Smad3 expression in NFPAs.

Notes: (A) Low expression of Smad3 in invasive NFPAs, (B) high expression of Smad3 in noninvasive NFPAs, (C) low expression of p-Smad3 in invasive NFPAs, (D) high expression of $\mathrm{p}$-Smad3 in noninvasive NFPAs; (A-D) magnification: 200x.

Abbreviation: NFPAs, nonfunctioning pituitary adenomas. 


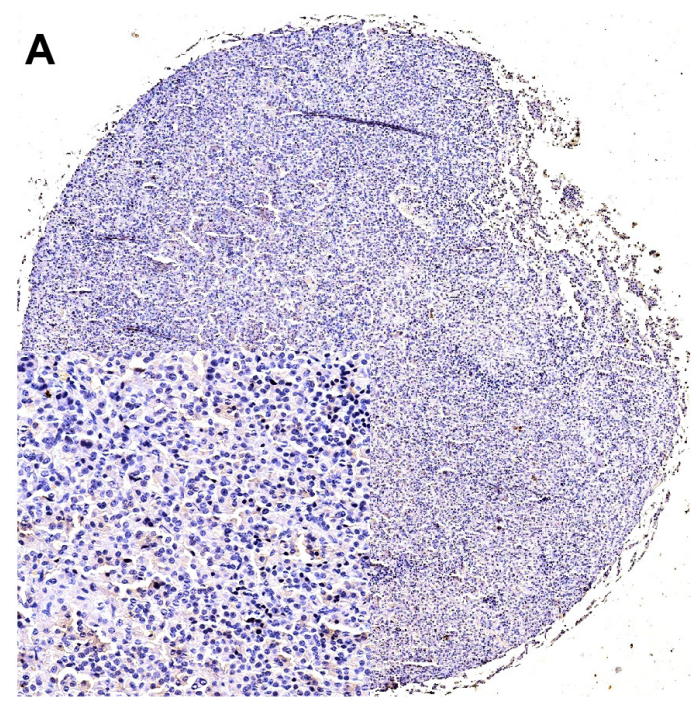

Figure 3 Smad4 expression in NFPAs.

Notes: (A) Low expression and (B) high expression; (A, B) magnification: 200×. Abbreviation: NFPAs, nonfunctioning pituitary adenomas.

that the Ki-67 index was markedly greater in invasive NFPAs than in noninvasive NFPAs $(P<0.05)$. Furthermore, Spearman's rank correlation analysis showed that the Ki-67 index was significantly correlated with $\mathrm{p}-\mathrm{Smad} 3$ levels $(P<0.05$, $r=-0.702)$, but not with the levels of Smad2, p-Smad2, Smad3, or Smad4 (Figure 4).

\section{Discussion}

In the present study, we investigated TGF- $\beta /$ Smad signaling and its proliferative activity in a large number of invasive and noninvasive NFPAs. We found that a low level of Smad3

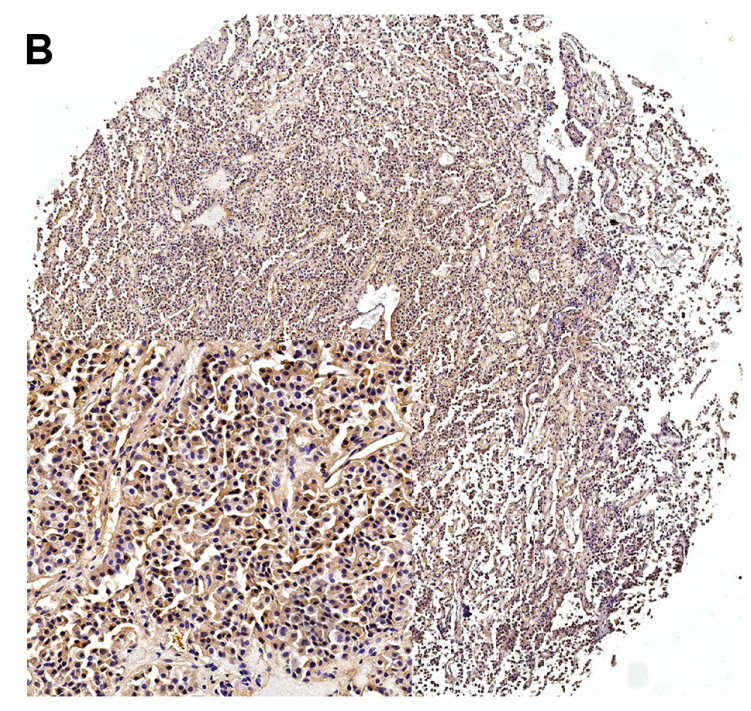

and p-Smad3 was associated with the invasion of NFPAs, and that proliferative activity was greater in invasive NFPAs than in noninvasive NFPAs.

Smad3 is a key factor in TGF- $\beta / \mathrm{Smad} 3$-mediated tumor suppressor effect. Wolfraim et $\mathrm{al}^{13}$ demonstrated that a reduction in Smad3 expression contributes to promote T-cell leukemogenesis. Moreover, Sodir et al ${ }^{14}$ reported that Smad3 deficiency promotes tumorigenesis in distal colon. In addition, it has been reported that $\operatorname{Smad} 3$ mutation in human cancer can functionally inactivate the Smad3 protein. ${ }^{15}$ In this study, we found that the expression of Smad3 and
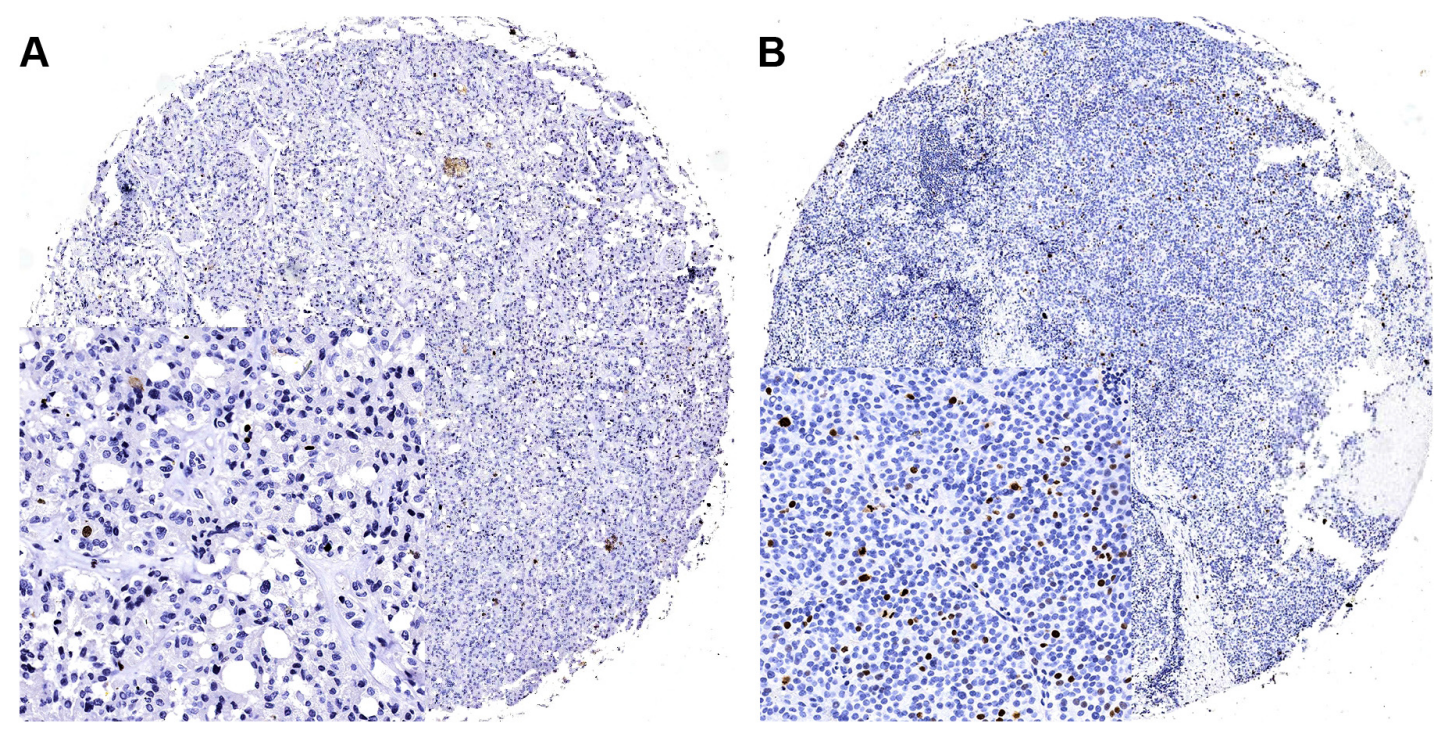

Figure $4 \mathrm{Ki}-67$ expression in NFPAs.

Notes: (A) Low expression in noninvasive NFPAs and (B) high expression in invasive NFPAs; (A, B) magnification: 200x.

Abbreviation: NFPAs, nonfunctioning pituitary adenomas. 
p-Smad3 was decreased in invasive NFPAs as compared with noninvasive NFPAs. Furthermore, we found that the Ki-67 index, an indicator for the proliferative activity of tumor cells, was markedly greater in invasive NFPAs than in noninvasive NFPAs and was significant correlated with p-Smad3 levels. These data suggest that Smad3 may act as a tumor suppressor in NFPAs and that TGF- $\beta$ signaling may contribute to the invasion of NFPAs.

Smad2 and Smad4 have been identified as tumor suppressors in various human tumors, ${ }^{16-19}$ including gastric, esophagus, liver, and breast cancers. Liu et $\mathrm{al}^{20}$ reported that Smad4 expression is reduced in ductal breast carcinoma as compared with surrounding uninvolved ductal breast epithelia, suggesting that Smad4 has a potential role in the development of breast carcinoma and is a potential prognostic marker of breast carcinoma. ${ }^{20}$ However, in the present study, we found that there was no significant difference in Smad2 and Smad4 protein levels between invasive NFPAs and noninvasive NFPAs. The discrepancy on Smad2 and Smad4 between PAs and other tumors suggests that the roles of Smad2 and Smad4 in PAs may be different and need to be further investigated.

\section{Conclusion}

In summary, this study showed that the protein levels of Smad3 and p-Smad3 are decreased in invasive NFPAs. This decrease in Smad3 and p-Smad3 may be associated with the invasion of NFPAs, and Smad3 and p-Smad3 may be useful biomarkers for the diagnosis of invasive NFPAs. Patients who have NFPAs with low expression of Smad3 and $\mathrm{p}-\mathrm{Smad} 3$ may benefit from aggressive treatment and close surveillance.

\section{Acknowledgments}

This work was supported by the National High Technology Research and Development Program of China (863 Program) (2014AA020610), the Research Special Fund for Public Welfare Industry of Health (201402008), and the National Natural Science Foundation of China (31200796).

\section{Disclosure}

The authors report no conflicts of interest in this work.

\section{References}

1. Daly AF, Rixhon M, Adam C, Dempegioti A, Tichomirowa MA, Beckers A. High prevalence of pituitary adenomas: a cross-sectional study in the province of Liege, Belgium. J Clin Endocrinol Metab. 2006; 91(12):4769-4775.
2. Fernandez A, Karavitaki N, Wass JA. Prevalence of pituitary adenomas: a community-based, cross-sectional study in Banbury (Oxfordshire, UK). Clin Endocrinol (Oxf). 2010;72(3):377-382.

3. Katznelson L, Alexander JM, Klibanski A. Clinical review 45: clinically nonfunctioning pituitary adenomas. J Clin Endocrinol Metab. 1993;76(5):1089-1094.

4. Colao A, Di Somma C, Pivonello R, Faggiano A, Lombardi G, Savastano S. Medical therapy for clinically non-functioning pituitary adenomas. Endocr Relat Cancer. 2008;15(4):905-915.

5. Wakefield LM, Roberts AB. TGF-beta signaling: positive and negative effects on tumorigenesis. Curr Opin Genet Dev. 2002;12(1):22-29.

6. Massague J. TGFbeta in cancer. Cell. 2008;134(2):215-230.

7. Massague J. TGFbeta signalling in context. Nat Rev Mol Cell Biol. 2012; 13(10):616-630.

8. Heldin $\mathrm{CH}$, Miyazono K, ten Dijke P. TGF-beta signalling from cell membrane to nucleus through SMAD proteins. Nature. 1997; 390(6659):465-471.

9. Nakao A, Afrakhte M, Moren A, et al. Identification of Smad7, a TGFbeta-inducible antagonist of TGF-beta signalling. Nature. 1997; 389(6651):631-635.

10. Zhenye L, Chuzhong L, Youtu W, et al. The expression of TGF-beta1, Smad3, phospho-Smad3 and Smad7 is correlated with the development and invasion of nonfunctioning pituitary adenomas. J Transl Med. 2014;12:71.

11. Knosp E, Steiner E, Kitz K, Matula C. Pituitary adenomas with invasion of the cavernous sinus space: a magnetic resonance imaging classification compared with surgical findings. Neurosurgery. 1993; 33(4):610-617; discussion 617-618.

12. Li ZY, Zhang XH, Chen Y, et al. Clinical significance of B7-H4 expression in matched non-small cell lung cancer brain metastases and primary tumors. Onco Targets Ther. 2013;6:869-875.

13. Wolfraim LA, Fernandez TM, Mamura M, et al. Loss of Smad3 in acute T-cell lymphoblastic leukemia. N Engl J Med. 2004;351(6):552-559.

14. Sodir NM, Chen X, Park R, et al. Smad3 deficiency promotes tumorigenesis in the distal colon of ApcMin/+ mice. Cancer Res. 2006;66(17): $8430-8438$

15. Ku JL, Park SH, Yoon KA, et al. Genetic alterations of the TGF-beta signaling pathway in colorectal cancer cell lines: a novel mutation in Smad3 associated with the inactivation of TGF-beta-induced transcriptional activation. Cancer Lett. 2007;247(2):283-292.

16. Hahn SA, Schutte M, Hoque AT, et al. DPC4, a candidate tumor suppressor gene at human chromosome 18q21.1. Science. 1996;271(5247): 350-353.

17. Wang LH, Kim SH, Lee JH, et al. Inactivation of SMAD4 tumor suppressor gene during gastric carcinoma progression. Clin Cancer Res. 2007;13(1):102-110.

18. Natsugoe S, Xiangming C, Matsumoto M, et al. Smad4 and transforming growth factor beta1 expression in patients with squamous cell carcinoma of the esophagus. Clin Cancer Res. 2002;8(6):1838-1842.

19. Yakicier MC, Irmak MB, Romano A, Kew M, Ozturk M. Smad2 and Smad4 gene mutations in hepatocellular carcinoma. Oncogene. 1999; 18(34):4879-4883.

20. Liu N-n, Xi Y, Callaghan MU, et al. SMAD4 is a potential prognostic marker in human breast carcinomas. Tumor Biol. 2013;35(1): $641-650$. 
OncoTargets and Therapy

\section{Publish your work in this journal}

OncoTargets and Therapy is an international, peer-reviewed, open access journal focusing on the pathological basis of all cancers, potential targets for therapy and treatment protocols employed to improve the management of cancer patients. The journal also focuses on the impact of management programs and new therapeutic agents and protocols on
Dovepress

patient perspectives such as quality of life, adherence and satisfaction. The manuscript management system is completely online and includes a very quick and fair peer-review system, which is all easy to use. Visit http://www.dovepress.com/testimonials.php to read real quotes from published authors.

Submit your manuscript here: http://www.dovepress.com/oncotargets-and-therapy-journal 